\title{
ETNOGRAFIA DAS ALTAS CLASSES MÉDIAS: UM ESTUDO NO BAIRRO BELA VISTA, EM PORTO ALEGRE/RS
}

\author{
Elena Salvatori ${ }^{1}$ \\ esal@portoweb.com.br
}

O objetivo da dissertaçao denominada "Nem tudo que reluz é ouro: estilo de vida e sociabilidade na construção de um espaço urbano de prestígio em Porto Alegre/RS"² foi conhecer o estilo de vida de certos segmentos médios da população de uma metrópole brasileira e sua repercussão no processo de apropriação/construção do espaço urbano. $\mathrm{O}$ universo foi delimitado a partir de em uma área habitacional agregadora de prestígio, localizada na cidade de Porto Alegre/RS - o bairro Bela Vista - tomando o eixo temático do sistema de localidade como a primeira definição dos sujeitos perante a cidade/sociedade. A identificação com a base territorial aparece, assim, como reveladora das representações dos sujeitos sobre sua própria condição social. Especialmente neste caso, a atuação destes moradores foi e é decisiva em conquistar, afirmar e manter esta distinção definida socialmente, e nisto os espaços públicos jogam um papel importante como suporte de uma performance característica.

\section{O bairro Bela Vista e seus moradores}

Em sua configuração física, o bairro Bela Vista assemelha-se à metade de um gomo de laranja, disposto sobre uma vertente de morro, cujo dorso é representado pelas Avenidas Nilópolis e Nilo Peçanha. Exatamente na confluência da Nilópolis e Nilo Peçanha está a praça Carlos Simão Arnt, mais conhecida como "pracinha da Encol", nome da construtora que a reurbanizou.

Esta porção de terra consiste em um "bolsão" que remanesceu desocupado em meio à área urbanizada da cidade, por muito tempo. Durante os anos 70, foi loteada e seus terrenos lançados no mercado imobiliário, tendo sua ocupação se acelerado na década de 80 , quando

\footnotetext{
1 Professora da Faculdade de Arquitetura da UFRGS, Doutoranda em Teoria e História da Arquitetura pela Universidad Politécnica da Cataluña (2000-2004).

${ }^{2}$ Dissertação de Mestrado defendida, em agosto de 1996, junto ao Pós-Graduação em Antropologia Social do IFCH/UFRGS.
} 
atingiu uma das maiores taxas de crescimento (quase quatro vezes o crescimento médio da cidade).

A possibilidade de adensamento populacional foi produzida por uma série de fatores, e incentivada tanto pela alteração da legislação urbanística e pela indução da ocupação da cidade em direção ao Shopping Iguatemi, no início dos anos 80, quanto pelas razões do mercado imobiliário local e brasileiro. Esta área habitacional captou uma demanda identificada com o apelo mercadológico, que acentuava a exclusividade e o privilégio de morar no local, em construções dirigidas para classes de maior poder aquisitivo. O padrão construtivo, as soluções formais, os serviços condominiais, surgidos na disputa pelo cliente, criaram novas exigências em relação ao conforto e beleza das edificações.

A população característica é representada pelos moradores dos condomínios verticais de alto padrão existentes no bairro que, por seu número, tornaram-se sua "marca registrada". Existem diferenciais de teor sociológicos, de visualização imediata através de levantamentos demográficos do Censo IBGE: a boa expectativa de vida de seus habitantes, a alta escolaridade dos adultos, os altos rendimentos médios dos chefes de domicílio, bem como um alto índice de moradias próprias e empregados domésticos em tempo integral. São compartilhadas, ainda, outras características comuns entre estes moradores, principalmente o fato de consistirem famílias nucleares ${ }^{3}$ de casais jovens, numa fase do ciclo familiar dedicada à criação de filhos ${ }^{4}$. Chama a atenção o alto índice de profissionalização feminina: todas as mulheres adultas pesquisadas trabalham. Quase metade de todos os adultos pesquisados é constituída de profissionais autônomos; os empregadores são minoria, um pouco mais de 10\%; o restante, são profissionais que podem ser classificados como pertencentes ao topo do mundo dos white-collars $^{5}$, ou de altos funcionários e empregados qualificados, de ascensão social recente, possível pela aquisição de capital cultural.

O universo estudado se enquadraria, portanto, nas chamadas "novas classes médias", que abrangem os "novos intermediários culturais" e, ainda, os "novos intelectuais", fascinados com a identidade, a apresentação, a aparência, o estilo de vida e novas experiências - o público, por excelência, produtor e consumidor dos novos bens e serviços simbólicos ${ }^{6}$,

\footnotetext{
${ }^{3}$ Família nuclear é definida, neste estudo, como aquela constituída somente do casal e seus filhos.

${ }^{4}$ Estes são os resultados de um estudo comparativo entre bairros, realizado preliminarmente à dissertação, baseado nos dados do Censo Demográfico IBGE de 1991.

${ }^{5}$ Esta é a classificação de MILLS, em Wright Mills: Sociologia, Coletânea organizada por FERNANDES, São Paulo, Ática, coleção Grandes Cientistas Sociais nº48, 1985

${ }^{6}$ Estas novas classes sociais são analisadas por FEATHERSTONE, em Cultura de consumo e pós-modernismo, São Paulo, Estúdio Nobel, 1995. Antes dele, ainda, por BOURDIEU, principalmente em La distinction: critique sociale du jugement, Paris, Ed. de Minuit, 1979. Bens e serviços simbólicos seriam aqueles destinados a demarcar uma posição social. Por exemplo: o estabelecimento de vistosas e dispendiosas moradias em bairros de
} 
cuja posse e consumo são capazes de situá-los socialmente em um contexto de grande mobilidade social. Aparecem movimentos próprios de trajetórias ascensionais, ou seja, a sociação em períodos de menor poder aquisitivo e uma progressiva dissociação/individualização à medida que a situação social vai melhorando.

\section{Ritmos integrativos cristalizados no espaço, protagonizados no tempo}

$\mathrm{Na}$ vida quotidiana destes moradores de condomínios verticais, que reproduz os ritmos da sociedade em que este grupo está inserido, são criadas polarizações espaço-temporais que acabam por definir os estritos territórios por onde transitam os indivíduos. Há um arranjo consagrado por este segmento - apartamento urbano e casa de lazer - que parece compor uma fórmula compatibilizadora das diversas necessidades espaciais decorrentes do trabalho e do lazer. Ambos os espaços fazem parte do ordenamento que rege sua vida, dividida entre tempo do controle - o tempo da produção, o tempo urbano, da racionalidade moderna - e o tempo do descontrole controlado - das férias, dos fins-de-semana, junto à Natureza, que satisfaria uma emocionalidade mais "primitiva".

Com freqüência, ainda, a dualidade público-privado aparece qualificada: espaços domésticos/internos seguros versus espaços públicos/externos inseguros. Parece ser cada vez maior a preocupação de estabelecer um perímetro de segurança cujo controle e vigilância seja total, com a finalidade de proteção pessoal e dos bens do grupo doméstico. Mais tarde, estes mesmos espaços exteriores ou públicos podem vir a ser relacionados com os espaços de liberdade individual dos jovens. Mas sua socialização, precocemente determinada pelas preocupações com a segurança física, é profundamente internalizada, e acaba por repercutir nas modalidades de sociabilidade desta população, circunscrita aos espaços percebidos como privados e controlados.

\section{Sociabilidade e Estilo de Vida nas esferas integrativas: doméstica, quotidiana e} pública

A verticalização dos prédios, em si, parece limitar a oportunidade dos contatos entre indivíduos, moradores de um mesmo edifício. Para muitos, esta limitação é desejável e atua como reguladora das relações de vizinhança compulsórias. Ou seja, tensões e conflitos inerentes à constituição desses grupos, principalmente pela necessidade de subordinar-se ao coletivo, ao social (mesmo nesta escala micro que confunde-se com o espaço privado, que é a

prestígio demarcam a superioridade social de seus moradores, muito além da mera satisfação de uma 
esfera, por excelência, da realização das individualidades), podem, assim, ser minimizados pela atitude de distanciamento.

Os "tipos" construtivos existentes no bairro parecem definir a tendência em direção à maior privatização dos espaços, à medida que o sujeito sobe na escala social. Ou seja, a previsão de menos espaços condominiais e maior qualidade e quantidade dos espaços privativos do apartamento, e mais sofisticados recursos de segurança, para prédios construídos mais recentemente, para os melhor aquinhoados.

Poderia ser estabelecida, ainda, uma escala de representações relativas às possibilidades de realização das individualidades, de acordo com o tipo de moradia. A casa individual aparece como a única que poderia realizar completamente a individualidade e o ideal de máxima privacidade, podendo ser visualizada como um ponto completamente auto referenciado, mas aparece como a solução mais insegura. O prédio de apartamentos viabiliza economicamente a moradia com certa qualidade, complica a individualidade, mas favorece certa privacidade ao fragmentar as circulações verticalmente. E aparece como a solução mais segura.

Para compreender as demandas por casas em condomínio horizontal (desejadas por todos os que projetam mudar-se) deve-se considerar a possibilidade revelada de desenvolver uma sociabilidade de molde tradicional. A "tradição", neste caso, aparece pela possibilidade de estreitamento de laços entre os vizinhos, pelo desenvolvimento de uma sociabilidade mais "natural", livre das tensões do dia-a-dia, e, ainda, na procura de uma relação mais direta com a "natureza". Claro que é uma reinterpretação: estes elementos são recriadas em ambiente protegido e selecionado, relaborados como ethos $^{7}$ modernizantes e elitizados, de natureza mais intimista.

O estabelecimento de sociabilidades também se dá em outras esferas espaciais. A rua é a primeira instância de caráter urbano para quem sai de casa e, por contraste à esfera doméstica, pode reportar mais imediatamente ao público, domínio do inevitável, do desconhecido e perigoso, do desamparo, do fora de controle, ao mesmo tempo que possibilita o contato com realidades exteriores e a experiência do novo. A localização da moradia em áreas topograficamente mais inacessíveis- que é uma realidade do bairro - dificulta esta experiência, ao mesmo tempo que protege a moradia. Mesmo para moradias localizadas em áreas mais planas, podem ser criadas barreiras artificiais que visam excluir a experiência da

necessidade básica.

7 "Ethos", na linguagem antropológica, é o sistema de valores referenciais do indivíduo de determinado grupo social, ligado diretamente aos afetos, instintos e emoções, internalizado através de processos de socialização. 
rua intencionalmente. Mas esta é uma situação vivenciada, quase sempre, como uma perda por parte dos pais, e referendada a uma situação presente de grande insegurança, ao mesmo tempo que reconhece um padrão de socialização que não pode ser repetido em relação aos seus próprios filhos.

Há, porém, um conjunto de ruas no bairro que merecem uma especial referência de seus moradores. Suas características topológicas conformam vias curtas, não ligadas diretamente à ruas de conexão inter bairros e, por isso, de menor circulação de veículos. Essas ruas são percebidas por seus moradores como mais exclusivas e são apropriadas, simbolicamente, como espaços quase privados e gerenciadas, em alguns casos, coletivamente. Neste universo, a rua Tauphik Saadi ocupa um especial lugar no imaginário local, tornandose, com o passar do tempo, quase que a corporificação do paradigma do estilo de vida mais imediatamente associado ao bairro Bela Vista. Esta rua é composta por duas quadras e está densamente ocupada por construções novas, que equilibram-se numericamente entre prédios de apartamentos e casas unifamiliares que foram construídos quase que num só período, conferindo-lhe uma certa homogeneidade de estilo. O prestígio associado a esta rua é alimentado por seus moradores crescentemente, criando, circularmente, novos pretextos de identificação que reforçam o sentido de pertencimento - como é hoje a decoração natalina empreendida por particulares, que tornou-se uma verdadeira atração turística na cidade.

Há outras, como a rua Jaraguá, que mantém a vida característica de uma vizinhança antiga e tradicional. Esta rede de vizinhança possibilitou a realização de festas comunitárias, como a de São João que, um pouco antes de iniciar a pesquisa, mereceu destaque nos órgãos de comunicação como um evento comunitário que identificava o bairro. E propicia, também, uma associação tácita que denominam de “autoproteção”, uma certa vigilância que é mantida pelos antigos moradores que passam muito tempo em casa, e iniciativas concretas de todos para prevenir, principalmente, roubos às residências.

Mas não se trataria de uma oposição simples entre os valores da Tradição e da Modernidade, senão uma relação dialógica. Pode-se observar que mesmo a metonímica assunção dos festejos de Natal junto a população deste bairro, festa de consumo cada vez mais carnavalizada e remetida a modelos internacionais, pode realizar valores matriciais, criar identidades de base local, ou "minicomunidades".

$\mathrm{O}$ "centro" $"$ do bairro abriga espaços públicos de sociabilidade cujas rotinas indicam as práticas de conservação da saúde e juventude física, tais como caminhadas ao ar livre e a 
prática de esportes, e, ainda, estabelecimentos de molde moderno, do tipo strip center, como constitutivos do estilo de vida internacionalizado desta população. A ambientação urbana deste "centro" do bairro teria como característica a sensação de abundância de espaços (propiciado pelas áreas abertas das praças, avenidas, clube e áreas de estacionamentos), vinculada à abundância de recursos, do poder econômico que instaura estes espaços, destinados ao usufruto de poucos privilegiados.

\section{Localidade territorial e processos de identidade social}

O sistema de localidade - primeiro eixo de análise do estudo - envolve a construção do espaço de modo valorativo, e dá lugar a processos distintivos que conformam o espaço objetivamente traçado de acordo com a subjetividade dos sujeitos.

Isto se percebe na questão dos limites geográficos do bairro - que para as pessoas pesquisadas está ligado mais diretamente à percepção de uma certa continuidade, que pode ser definida tanto em termos edilícios e urbanísticos quanto social. Por isso, perguntadas sobre sua concepção acerca dos limites do bairro, respondem agregando mentalmente áreas vizinhas cujo padrão construtivo e sócio-econômico é assemelhado, enquanto são traçadas, mentalmente, organizações geométricas simplificadas.

Percebe-se recorrentes os significados atribuídos ao espaço do bairro por estes novos moradores: é o íntimo, o aconchegante, o redondo, o nicho bonito, ordenado e auto-suficiente ao abrigo do "tentáculo" desordenado da cidade, porção espacial que a "cobra" esqueceu, cuja homogeneização social é fator de segurança e que possibilita uma sociabilidade específica. A praça localizada no cruzamento que é ligação com outros bairros, coloca-se metaforicamente, por isto mesmo, como "sala de visitas", espaço de ordenação das relações sociais intermediadas pela imagem do que se quer mostrar a um "outro" genérico. O "centro" do bairro é formado pela combinação "lazer-consumo", através dos estabelecimentos de consumo diferenciado junto à áreas de lazer e esportivas. Este "lazer-consumo" parece ser o "tom" dominante do ethos de classe da população pesquisada, cujo projeto de vida prevê a dedicação de grande parte de seus esforços para a construção de um estilo de vida que comporte, cada vez mais e como finalidade, formas de lazer mais qualificado e dispendioso.

A cosmologia casa-cidade desdobra-se no continuum que reserva agora ao bairro o papel daquela, ao colocar-se como um espaço razoavelmente controlável, e onde as relações são estabelecidas entre socialmente iguais. Isto é, a sociabilidade eletiva da casa estende seus

\footnotetext{
${ }^{8}$ Este "centro" está, com exceção da pracinha e alguns poucos estabelecimentos, localizado em área limítrofe
} 
domínios; o bairro recria o modo urbano de uma cidade pequena, desta vez, com os valores de cidade grande - o individualismo, a reserva entre os vizinhos próximos, o sentido de privacidade, as relações de vizinhança entabuladas em um nível de identidade mais geral. Os mecanismos de controle, que numa cidade pequena têm conotação moral, neste caso são deslocados para a seletividade sócio-profissional e econômica.

É traçada, assim, uma cartografia simbólica do espaço urbano: a cidade é mapeada de acordo com as representações do estágio da inserção social das populações que habitam as diferentes porções e, em diversos momentos, as falas denunciaram estas questões ascensionais - antigos bairros, representantes de um tempo passado e de uma situação social menos favorecida são qualificados pejorativamente. A identidade pode ser produzida, em parte, por esta localização geográfica que se confunde com lugar social, capaz de realizar em homologia a identificação com pessoas consideradas superiores, pertencentes a uma categoria social desejável. E, por outro, pela rejeição às situações socialmente marginalizadas, pela negação, talvez, das situações de pobreza e necessidade que poderiam estar na trajetória de alguns dos pesquisados ou de suas famílias de origem.

A adesão social à novas áreas de moradia lançadas pelo mercado imobiliário podem vir a obedecer a modelos paradigmáticos de "bem viver", que cria novas exigências atreladas ao espaço habitacional, que podemos traduzir, para o segmento estudado, por ambiente limpo, organizado visualmente e não muito denso, de prédios novos e modernos, ao mesmo tempo que faz referência à necessidade da presença da natureza, em espaços "verdes" ativos, os parques, ou passivos - os jardins, a "vista", qualidades imputadas ao bairro Bela Vista.

As possibilidades de consumo exibidas pelo bairro faz parte das representações sobre o estilo de vida ativo, moderno e dispendioso dos moradores do bairro, mas parece estar, na maior parte das vezes, exatamente nesta posição: possibilidade que não se realiza de modo objetivo e pleno. Isto estaria ligado a um "tipo" urbano, que se conforta apenas com a possibilidade. A atração exercida pelo bairro parece estar, por isso, relacionada mais com o consumo virtual da imagem do consumo que é associado a uma fração de classe em franca ascendência social, do que com o próprio consumo objetivo.

Se o estabelecimento de territorialidades sócio-geográficas aparece como um fator identitário em relação à totalidade da cidade, por outro, estas mesmas diferenciações aparecem internamente. O próprio discurso dos pesquisados vai conformando um mapa de exclusões que permite quase classificar os espaços públicos de praças em função da distinção 
entre a clientela específica de cada uma, num movimento desde a visibilidade total (representada pelos espaços da pracinha da Encol e adjacências) até a "privatização" maior ou menor dos demais espaços, que são usufruídos por quem não pretende se identificar com a "massa". Ficam bastante claros os movimentos de sociação ou dissociação que estão na origem desta identificação, ou negação, de determinados espaços, os espaços sendo abandonados à medida que se popularizam, assim como a moda, que está sempre procurando novos padrões distintivos.

Um dos espaços menos freqüentado é o da praça Bela Vista, localizada na parte mais alta do bairro, no centro de um conjunto de quarteirões formado por ruas transversais e periféricas às vias principais. O prestígio deste espaço é construído duplamente: pela privatização espacial (a exemplo de outras ruas de uso restrito no bairro) e pela exclusividade social (que associa uma certa posição geográfica a um nome/posição social). Um dos moradores dos arredores desta praça atribui aos "pioneiros" do bairro a criação de uma ordem modelar, desejosa de ser imitada por indivíduos de camadas menos favorecidas ou em processo de ascensão. Seu discurso pode ser relacionado diretamente à percepção da existência de espaços que propiciam uma visibilidade maior e a necessidade desses "novos" moradores (também num sentido ascensional) de serem vistos, comparativamente à porção "discreta" onde habita, metaforicame nte colocada no "alto".

Considerando que o estabelecimento da territorialidade - a apropriação do espaço vivenciado quotidianamente - diz respeito não somente aos espaços contíguos à moradia, mas, ainda, ao traçado do universo objetivamente acessível, constata-se um alto grau de individualização no desenho deste território pessoal. A seletividade individual pode operar reduções que visam simplificar as rotinas, dentro de objetivos de eficácia. Pode, ainda, desconsiderar certas "escalas" de relação social, selecionando as realidades que considera dignas, ou seguras, de serem vividas. Ou seja, o mundo individual é demarcado como uma "constelação de lugares", cujas ligações podem desconsiderar espaços intermediários, percorridos por automóveis particulares, ou aviões. Alguns pesquisados, certamente, transitam com mais familiaridade por New York, Miami ou outras metrópoles, do que em Porto Alegre. A seletividade social e espacial pode ser relacionada à etapa específica da vida do indivíduo que, de acordo com os resultados deste estudo, parece tender para uma individualização cada vez maior a medida que ascende na escala social. Mas pode ser, ainda, ligada à existência de certas prescrições de classe que atuam como reguladoras das relações quotidianas, prescrições estas que estão limitadas aos espaços sociais de pertencimento. 


\section{A moradia, espaço e arranjo}

A quase totalidade das moradias dos pesquisados é própria; a posse do imóvel parece ser essencial a este grupo e a época da aquisição coincide, em dois terços dos casos, com o casamento. A necessidade de ter um imóvel próprio para moradia, além de aferir os progressos profissionais e financeiros, é explicada em relação às necessidades de individualizar, ao máximo, este espaço. Subjacente ao desejo de possuir um imóvel próprio parece estar, ainda, a necessidade de fixar uma base espaço-territorial, que pode significar a conquista da estabilidade social e econômica ou a chegada a determinado patamar. No universo estudado, porém, esta gregariedade é histórica: a maioria dos entrevistados morou em poucas casas ao longo de sua vida. Existe, ainda, uma grande preocupação em fazer correto, e mais que isso, bonito, para o que são contratados especialistas, como decoradores e arquitetos.

Com relação ao espaço doméstico, pode-se afirmar que existe tendência para a ocorrência de espaços suplementares, relacionados, em primeiro lugar, com o lazer privativo e, em segundo, com a existência de locais de trabalho e estudo, para o casal ou seus filhos. A situação objetiva de poder expandir o espaço, por exemplo, sobre pátios de apartamentos térreos ou fechando parte de um terraço, é bastante valorizada. E existe, ainda, a maior privatização dentro da própria moradia, por exemplo, através da existência de sanitários exclusivos por dormitório. A medida que as moradias crescem de tamanho, espaços "íntimos" acabam por ser, crescentemente, separados dos espaços "sociais", ou seja, voltam a haver espaços especializados para recepção - coisas das moradias de "antigamente".

Aparece como característica a existência de sacadas com churrasqueiras. A presença de espaços abertos como as sacadas atenuam, ainda, a dicotomia entre espaço artificial/fechado e espaço natural/aberto, através da criação artificial de "solo", o pátio elevado horizontalizando a expansão de espaços confinados verticalmente. A sacada ou o terraço representaria a parte "natural" da moradia, ligada à atividades mais relacionadas ao espaço aberto, consideradas impróprias de desenvolver em ambiente fechado - como fazer churrasco.

Alguns elementos das casas idealizadas da infância (como locais de segurança, de descoberta do mundo ou do estabelecimento da continuidade) estão presentes no atual contexto espacial deste universo. Os prédios de formas arrojadas e revestimentos de elementos que salientam ângulos e volumes de composições geométricas, supondo valores de 
natureza racional, podem ser encimados por "chalés de montanha" ou "casas de campo" a maior parte das vezes. Estas coberturas aparecem como a evocação de um estilo de vida "natural", no topo de montanhas artificialmente construídas, em ambientes de "natureza" absolutamente controlada.

A decoração da moradia, que aparece nos relatos como pertencente à esfera do efêmero, é de domínio quase que exclusivamente feminino, a não ser que o marido seja um especialista, como um arquiteto. Neste sentido, parece haver a necessidade de delimitar espaços físicos "masculinos" não cotidianos, como a churrasqueira externa, salientando a excepcionalidade da situação. À mulher são associados os itens relacionados com o tempoespaço normal do cotidiano e das esferas domésticas (elaboração do cardápio diário, a arrumação e o arranjo doméstico, o trato com os empregados domésticos, a organização e execução das rotinas quotidianas e os espaços de serviço da moradia). O homem associa-se com os eventos excepcionais, com o planejamento estratégico dos investimentos econômicos e financeiros, e com os espaços exteriores, com o tempo extraordinário do lazer, mais relacionado ao espaço "natural" e esferas sociais ou públicas, mesmo da habitação.

Os espaços públicos da moradia, ou aqueles onde dão as inter relações com indivíduos de outros grupos domésticos, são os que foram chamados neste estudo de "espaços de representação", pois já incluiriam uma esfera bastante personalizada, ou seja, de identidade referenciada à papéis sociais mais gerais ${ }^{9}$. Estas áreas "sociais" funcionam, ainda, como controladoras do nível de interação, garantia das imagens pessoais produzidas, limite que só é ultrapassado por especial assentimento dos sujeitos. Grande parte das moradias demonstram a preocupação com o estabelecimento de um estilo ou uma imagem para estas áreas de representação, que não se esgota nas chamadas áreas "sociais" da moradia. Esta preocupação estende-se aos espaços mais privativos e áreas de serviço. Pode-se considerar a hipótese de que há uma penetração estilística em todos os aspectos da vida quotidiana que leva à ordenação do mundo privado à feição do público, e vice versa, num efeito circular que interliga estas esferas.

Os espaços de recepção das moradias estudadas ou sua "área social", estão conformados à interação social em torno da conversação e da comensalidade. Qualquer evento supõe compartilhar bebida e comida, e o "bar", móvel destinado à guarda de bebidas alcoólicas - que muitas vezes ficam à vista - é quase unanimidade em todas as moradias visitadas. A evocação de um passado de lazer proporcionado pelas famílias mais abastadas 
levanta a hipótese de que esta predisposição para receber que encontramos no universo poderia ser, então, parte da imagem de um estilo de vida superior (situação que, por um motivo ou outro, não se realiza) ficando, de fato, reservada aos de melhor poder aquisitivo.

$\mathrm{O}$ arranjo das moradias pesquisadas sugere, inicialmente, a díade "abundância" e "suficiência", conceitos que podem ser utilizados para expressar a primeira impressão que o arranjo e decoração das moradias podem produzir no observador - no caso em estudo, divididas igualmente entre uma e outra impressão. Verifica-se uma tendência em direção à acumulação e à aquisição de bens simbólicos - objetos, obras de arte, mobiliário sob medida na proporção do crescimento do poder aquisitivo e que se torna mais visível com o passar do tempo. Esta tendência pode ser contrabalançada por outra de base mais ascética, que vai definir poucos e eficazes elementos simbólicos - principalmente obras de arte - calcados na diferenciação de base cultural, mesmo que surgido em contexto de menor disponibilidade de recursos. Ou seja, a falta de recursos pode ser compensada ou denegada através da adoção de parâmetros de gosto superior, que justifiquem ambientes despojados com a máxima intencionalidade estilística. Parece haver, ainda, uma diferença de base geracional que sugere a hipótese de haver uma tendência na geração mais nova em acumular objetos de prestígio a medida de seu progresso financeiro, enquanto que a geração anterior, a partir do estabelecimento de um patamar de suficiência, tende ao alargamento da base econômica.

Assim como existe uma diferenciação de base econômica, para a qual pode ser invocada outra, de base cultural, também aparece uma diferenciação propriamente cultural, de acordo com as preocupações básicas da decoração, caso esta seja produzida em função "dos outros" ou em função "de si mesmo". Haveria uma decoração especialmente preocupada em localizar sincronicamente a posição social do indivíduo perante os demais indivíduos, formulada segundo critérios de senso comum. Esta seria a decoração dos que empreenderam trajetórias de ascensão social, que não teriam suficiente capital cultural ou segurança para definir estilos individuais, nem desenvolvem níveis perceptivos mais aprofundados. Sua antítese seria a decoração dotada de significados individuais, cujos elementos podem construir a história do sujeito ou do grupo e está baseada na afirmação de um gosto individual, numa especial elaboração da relação do sujeito com os meio ambiente e os objetos que o rodeiam.

Os valores da modernidade parecem estar presentes mais diretamente naqueles exemplos que tomam a arte contemporânea como leit motiv da decoração doméstica. Ser moderno aparece como ser de vanguarda, ter mobilidade, fazer rupturas com os estilos

\footnotetext{
9 "Espaços de representação" é um conceito desenvolvido por PEZEU-MASSABUAU, em La maison, espace
} 
tradicionais de viver, estar sintonizado com o seu tempo, ou seja, ser portador de contemporaneidade.

Aqueles que utilizam elementos de estilos de épocas passadas e mobiliário antigo salientam os valores da permanência e da continuidade, mesmo que estes sejam poucos elementos em meio a objetos e obras de arte mais contemporânea. Esta ambientação pode afirmar uma identidade pertencente a uma linhagem social mais perene. Em outras circunstâncias, porém, esta identidade pode ser "fabricada", ancorada em testemunhos de um passado que jamais existiu. Mas, antes de mais nada, a utilização de móveis e objetos antigos parece reafirmar o valor e a beleza da continuidade perante uma realidade presente de fragmentação - decorrente dos próprios processos de ascensão.

Para os estreantes em uma nova classe social, ou os "novos ricos", existe sempre o risco de demonstrar um gosto deslocado. Mas a expansão da classe média e a democratização dos conhecimentos via moderno sistema de comunicações altera a lógica de consumo imposta por uma elite social e intelectual ${ }^{10}$. É possível reconhecer uma nova tendência na decoração de interiores, que não está preocupada com a linguagem da autenticidade ou da legitimidade, seja dos objetos modernos ou antigos - que soluciona o enquadramento do gosto e prova, ainda, a capacidade destas novas camadas sociais em impor diferentes hierarquias simbólicas. Esta seria a utilização de móveis e elementos envelhecidos artificialmente através de pinturas especiais, que destinam-se a evocar a antigüidade sem, no entanto, chegarem a ser falsificações. Ao contrário, deve-se perceber que é uma reinterpretação, uma ambientação quase teatral, na qual as pátinas passam a evocar um passado inespecífico, uma moradia ancestral que nunca existiu, uma saudade sem substância, mas parecem reafirmar antes de tudo a beleza de ter lembranças.

\section{Conclusões}

Temos assim, uma grande diversidade nas representações associadas à estilização do cotidiano, que são acionadas seletivamente em função de movimentos de identificação ou diferenciação e, ainda, na procura de controlar o tempo fugaz da vida moderna. As representações dos entrevistados podem parecer organizadas em oposições simples, mesmo recurso de racionalidade que organiza um tempo linear de progresso. O primeiro grupo seria o que associa Presente, Tempo Produtivo, Espaço Urbano-Global, Eficácia, GregarismoControle, Fragmentação, Modernidade-Mudança; o segundo, relacionando Passado, Tempo 
do Lazer, Espaço NaturalLocal, Frouxidão, Nomadismo-Descontrole, Unidade, TradiçãoContinuidade. Estas representações, porém, fazem parte de uma complexa superposição temporal que imprime uma dinâmica característica ao universo, tensionada pela inevitabilidade dos processos de modernização e a necessidade de construir a continuidade. Assim é que o "estoque" de padrões tradicionais é acionado regularmente; estes valores, porém, jamais poderão ser vivenciados senão em situação de reatualização, de ressignificação, de relaboração - pois o valor-mudança está definitivamente incorporado ao ethos deste grupo.

O bairro Bela Vista parece obter sua popularidade ao proporcionar um suporte físico adequado para que estas imagens se superponham, em experiências construídas e reeditadas por seus moradores. Poderia ser, segundo estas representações, um enclave de Modernidade que realiza um ideal de vida mais qualificada e saudável e possibilita práticas de consumo da caráter lúdico, moderno e, ao mesmo tempo, um oásis que possibilita a vivência das antigas sociabilidades urbanas ligadas às antigas formas "naturais" de vizinhança da Tradição, em que a pracinha desempenha um papel fundamental - já ao gosto da Pós-modernidade.

Por outro lado, as possibilidades de consumo-lazer exibidas pelo bairro faz parte das representações sobre este seu estilo de vida, mas, para a maior parte dos moradores e de outros freqüentadores da "pracinha”, é um ideal que não se realiza de modo pleno. A atração exercida pelo bairro parece estar, por isso, relacionada mais com o consumo virtual da imagem do consumo que é associado a uma fração de classe em franca ascensão social, do que com o próprio consumo objetivo ${ }^{11}$.

A imagem do bairro Bela Vista, forjada coletivamente desde várias fontes, e coletivamente incorporada por seus novos moradores, que reúne e atribui poder econômico, distinção social, estilo de vida moderno, um grande grau de autonomia, mobilidade e internacionalização, disposição para o lazer, hábitos de consumo sofisticados, pode ser considerado um exemplo bem sucedido em eficácia simbólica, pela unanimidade alcançada junto à população dos estratos médios da cidade de Porto Alegre.

\footnotetext{
${ }^{11}$ Quanto a este aspecto, lembremos significativos fatos como as dificuldades financeiras da Construtora Encol, que forneceu o nome popular à "pracinha”, e a concordata do supermercado Febernati, o dos "importados mais baratos da cidade”, divulgados em 1997 pela imprensa local.
} 